\title{
Increased sensitivity of NS1 ELISA by heat dissociation in acute dengue 4 cases
}

\author{
Sibelle Nogueira Buonora ${ }^{*}$, Flavia Barreto dos Santos ${ }^{2}$, Regina Paiva Daumas ${ }^{3}$, Sonia Regina Lambert Passos ${ }^{1}$, \\ Manoela Heringer da Silva ${ }^{2}$, Monique Rocha de Lima ${ }^{2}$ and Rita Maria Ribeiro Nogueira ${ }^{2}$
}

\begin{abstract}
Background: Dengue is an acute febrile illness considered the major arboviral disease in terms of morbidity, mortality, economic impact and dissemination worldwide. Brazil accounts for the highest notification rate, with circulation of all four dengue serotypes. The NS1 antigen is a dengue highly conserved specific soluble glycoprotein essential for viral replication and viability that can be detected 0 to 18 days from the onset of fever (peak first 3 days). It induces a strong humoral response and is known as a complement-fixing antigen. Lower NS1 test sensitivity occurs in secondary dengue infections probably due to immune complex formation impairing antigen detection by ELISA.
\end{abstract}

Methods: We compared the sensitivity of NS1 ELISA in heat dissociated and non-dissociated samples from 156 RT-PCR confirmed acute dengue-4 cases from 362 prospectively enrolled patients.

Results: Secondary infections accounted for 83.3\% of cases. NS1 ELISA was positive in 42.5\% and indeterminate in 10. $2 \%$ of dengue- 4 cases. After heat dissociation, 7 negative and 16 indeterminate samples turned positive, increasing the overall test sensitivity to $57.7 \%$.

Conclusions: Although it is time consuming and requires the use of specific laboratory equipment, NS1 ELISA combined with heat dissociation could be a slightly better alternative for triage in suspected dengue cases.

Keywords: NS1 ELISA, Accuracy, Dengue diagnosis, Immune complex dissociation, DENV-4

\section{Background}

Dengue is an acute febrile illness considered the major worldwide arboviral disease, in terms of morbidity, mortality, economic impact and dissemination [1]. Dengue occurs in all non-polar continents [2] and is an important public health concern in tropical and subtropical regions mainly in Asia and Americas [3, 4]. Estimates account for 390 million dengue infections per year of which 96 million present clinical manifestations [5]. The disease is endemic in 100 countries and approximately $40 \%$ of the world population is at risk of dengue infection [1]. By the end of the $20^{\text {th }}$ century, Brazil became the country with the highest notification rate, accounting for 98.5\% of the American continent's reported cases and the highest fatality rate in the sub region [1]. Since 2008, all

\footnotetext{
* Correspondence: sibellebuonora@gmail.com

${ }^{1}$ National Institute of Infectious Diseases Evandro Chagas, Laboratory of Clinical Epidemiology, Oswaldo Cruz Foundation, Av. Brasil, 4036 sala 201 A Manguinhos, Rio de Janeiro CEP: 21040-361, Brazil

Full list of author information is available at the end of the article
}

four dengue serotypes (DENV-1 to DENV-4) can be found in the country [6].

NS1 Ag is a dengue highly conserved specific soluble glycoprotein essential for viral replication and viability that can be detected in dengue patients from day 1 up to 18 days after fever onset [7] with peak sensitivity in the first 3 days of fever onset [8]. It induces a strong humoral response and is known as a complement-fixing antigen [9].

Previous studies have evaluated the usefulness and the accuracy NS1 tests [10-14]. According to da Costa et al. the main factors influencing the diagnostic accuracy are the type of infection (primary versus secondary), viral serotype, geographical origins of samples, and the timing of sample collection [12].

Low NS1 test sensitivity in secondary dengue infections may be attributed to high levels of IgG in anamnestic response with immune complex formation impairing antigen detection by ELISA $[9,15]$. Some studies have also noticed lower NS1 sensitivity in DENV-4 compared to 
other serotypes, in both primary and secondary dengue $[12,13]$. Furthermore, immune complex dissociation techniques have proven to be important for the early diagnosis of HIV infections and most recently DENV $[9,16]$. A study conducted in Rio de Janeiro with DENV-4 cases analyzed acid treatment/neutralization and heat dissociation, with a better performance for the latter [9]. In the present study, we compared the sensitivity of NS1 ELISA in heat dissociated and non-dissociated samples from acute DENV-4 patients.

\section{Methods}

This study is part of a prospective cross-sectional pragmatic diagnostic study of clinical and diagnostic algorithms for dengue diagnosis conducted at Rio de Janeiro, Brazil during the 2013 dengue epidemic season (March and April). We used the Standards for Reporting of Diagnostic Accuracy Study (STARD)
Guideline [17]. Eligible adult patients who presented to a public outpatient unit (Unidade de Pronto Atendimento-UPA 24H) within $72 \mathrm{~h}$ of a febrile illness without an evident source of infection were interviewed and examined by the investigators. At the time the study was carried out there were no evidences that other Flaviviruses, such as Zika were circulating in Rio de Janeiro [18].

Blood samples were collected and sera stored at $-70{ }^{\circ} \mathrm{C}$ until the tests. The index test (Platelia Dengue NS1 Ag-ELISA), specific IgG and confirmatory RT-PCR were all performed at the Flavivirus Regional Reference Laboratory, IOC, FIOCRUZ.

The Platelia" Dengue NS1 Ag-ELISA (Bio-Rad Laboratories, Marnes-La-Coquette, France) was performed in all samples according to the manufacturer's instructions and described elsewhere, briefly the test is based on a one-step sandwich format microplate enzyme

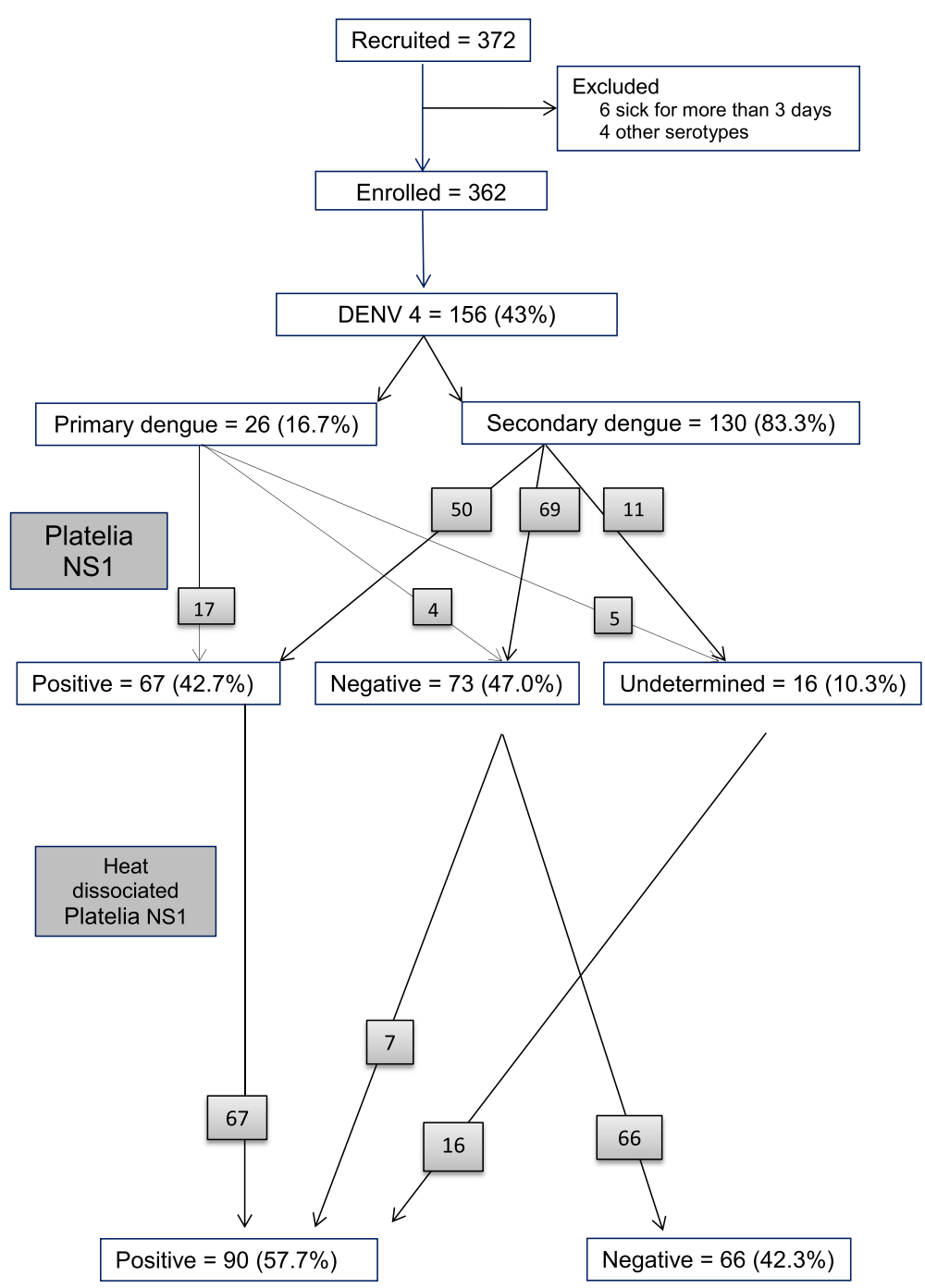

Fig. 1 STARD [17] diagram DENV-4 patients in Rio de Janeiro, 2013 
Table 1 DENV-4 NS1 performance according to type of infection and method, Rio de Janeiro, 2013

\begin{tabular}{|c|c|c|c|c|}
\hline \multirow{2}{*}{$\begin{array}{l}\text { Platelia }^{\mathrm{TM}} \\
\text { Dengue NS1 } \\
\text { Ag-ELISA }\end{array}$} & \multirow[t]{2}{*}{ Results } & \multicolumn{2}{|c|}{ Type of infection } & \multirow{2}{*}{$\begin{array}{l}\text { Total } \\
N=156\end{array}$} \\
\hline & & $\begin{array}{l}\text { Primary } \\
N=26\end{array}$ & $\begin{array}{l}\text { Secondary } \\
N=130\end{array}$ & \\
\hline \multirow[t]{3}{*}{ Non-dissociated } & Positive & $\begin{array}{l}17 \\
(65.4 \%)\end{array}$ & $\begin{array}{l}50 \\
(38.4 \%)\end{array}$ & $\begin{array}{l}67 \\
(43.0 \%)\end{array}$ \\
\hline & Negative & $\begin{array}{l}4 \\
(15.3 \%)\end{array}$ & $\begin{array}{l}69 \\
(53.3 \%)\end{array}$ & $\begin{array}{l}73 \\
(46.8 \%)\end{array}$ \\
\hline & Indeterminate & $\begin{array}{l}5 \\
(19.2 \%)\end{array}$ & $\begin{array}{l}11 \\
(8.3 \%)\end{array}$ & $\begin{array}{l}16 \\
(10.2 \%)\end{array}$ \\
\hline \multirow[t]{2}{*}{ Heat dissociated } & Positive & $\begin{array}{l}22 \\
(84.6 \%)\end{array}$ & $\begin{array}{l}68 \\
(52.3 \%)\end{array}$ & $\begin{array}{l}90 \\
(57.7 \%)\end{array}$ \\
\hline & Negative & $\begin{array}{l}4 \\
(15.4 \%)\end{array}$ & $\begin{array}{l}62 \\
(47.7 \%)\end{array}$ & $\begin{array}{l}65 \\
(42.3 \%)\end{array}$ \\
\hline
\end{tabular}

immunoassay to detect DENV NS1 antigen in human serum [10].

The same samples were further submitted to the heat dissociation method when $50 \mu \mathrm{L}$ of the serum was added to $100 \mu \mathrm{L}$ of RNA/DNAse free water and heated in a boiling water bath for five minutes, as described previously [9].

We defined as secondary cases those patients who presented positive IgG results within $72 \mathrm{~h}$ onset of disease [19]. The Dengue Virus IgG DxSelect ELISA (Focus Diagnostics, California, USA) was performed according to the manufacturer's instructions in all samples to diagnose secondary dengue cases.

The viral RNA detection by RT-PCR was performed according to the technique described elsewhere [20]. Laboratory personnel were blinded to other laboratory data such as Platelia "mengue NS1 Ag-ELISA, IgG and RT-PCR when executing a specific test. DENV infections by other serotypes were excluded. Exploratory analysis was performed using $\mathrm{SPSS}^{\odot}$ v 17.0 (SPSS Inc., Chicago, Illinois). The MedCalc ${ }^{\odot}$ 14.8.1 program was used to calculate $95 \%$ confidence intervals (CI) for the Platelia Dengue NS1 Ag-ELISA sensitivity.

\section{Results}

A total of 372 ambulatory patients were enrolled, with 10 exclusions (six presenting symptoms for more than 3 days and four due to infections to other DENV serotypes. The remaining 362 patients had their clinical profile previously described [21]. Briefly, 55.6\% were female, the median age was 33 years old (ranging from 18 to 83 ) and the median time from the onset of illness was two days.

The RT-PCR identified DENV-4 in 42.8\% (156/362) of the cases. From those, $16.7 \%(26 / 156)$ were classified as primary infection cases and $83.3 \%$ (129/156), as secondary ones, Fig. 1.

The NS1 ELISA performance as described by the manufacturer's protocol in the 156 DENV-4 cases resulted in $43.0 \%(67 / 156)$ of positive cases, $46.8 \%(73 / 156)$ negative and $10.2 \%(16 / 156)$ indeterminate (Table 1). After the heat dissociation process, all 67 DENV-4 positive cases remained positive; 7 negative all 16 indeterminate cases became positive, as also described by Lima et al [9]. These results could jeopardize the theory of IgG immune complex formation; however the increase in sensitivity in those cases might occur due to an increased detection of monomeric NS1 forms [22].

\section{Discussion}

In our study, the overall sensitivity of the NS1 test in DENV-4 cases was $47.8 \%$, quite similar to the $46.6 \%$ obtained by Lima [9], but lower than the $58 \%$ sensitivity obtained in da Costa's meta-analysis [12], Table 2. This low overall sensitivity may be caused by the South American virus polymorphism lower overall viremia and lower NS1 secretion $[12,13]$. The differences in the sensitivities in primary and secondary infections in our case before heat dissociation $80.9 \%$ vs $42.0 \%$ were also found in da Costa's meta-analysis (94.6\% vs $66 \%$ ) [12]. Even attenuating the influence of secondary infections by heat dissociation, the sensitivities obtained were still low.

Table 2 Sensitivity of Platelia" ${ }^{\text {TM }}$ Dengue NS1 Ag-ELISA in acute DENV-4, Rio de Janeiro, 2013

\begin{tabular}{|c|c|c|c|c|}
\hline & \multicolumn{2}{|c|}{ Platelia $^{\text {TM }}$ Dengue NS1 Ag-ELISA } & $\begin{array}{l}\text { Sensitivity } \\
(95 \% \mathrm{Cl})\end{array}$ & $p$-value \\
\hline \multirow[t]{2}{*}{ Overall sensitivity } & \multicolumn{2}{|c|}{ Non-dissociated } & $\begin{array}{l}47.8 \\
(39.3-56.4)\end{array}$ & $p<0.001$ \\
\hline & \multicolumn{2}{|c|}{ Heat dissociated } & $\begin{array}{l}57.7 \\
(49.5-65.5)\end{array}$ & \\
\hline \multirow[t]{4}{*}{ Type of infection } & \multirow[t]{2}{*}{ Primary } & Non-dissociated & $\begin{array}{l}80.9 \\
(58.1-94.6)\end{array}$ & $p<0.001$ \\
\hline & & Heat dissociated & $\begin{array}{l}84.6 \\
(65.1-95.6)\end{array}$ & \\
\hline & \multirow[t]{2}{*}{ Secondary } & Non-dissociated & $\begin{array}{l}42.0 \\
(33.0-51.4)\end{array}$ & $p<0.001$ \\
\hline & & Heat dissociated & $\begin{array}{l}52.3 \\
(43.3-61.1)\end{array}$ & \\
\hline
\end{tabular}


We demonstrated significant sensitivity increases after dissociation in both types of DENV-4 infections in agreement with other studies that used unspecific dengue serotype acid dissociated NS1 samples [15, 23].

This study has advantages since it was prospectively executed, the samples were clinically and laboratorially well characterized, and collected during a single outbreak in one outpatient unit increasing the chance of genotypic similarity, quite different from the previous study which was carried out during a 17 month period when genotypic heterogeneity is possible [9]. We were able to demonstrate the advantages of incorporating heat dissociation to the Platelia ${ }^{\mathrm{m}}$ Dengue NS1 Ag-ELISA kit in order to increase its sensitivity, mostly in settings where circulating DENV-4 can be an issue. The study limitation was the lack of heterogeneity of viral strains that impairs the generalization of the results in other epidemic settings.

\section{Conclusions}

Although time expending and the requirement of specific laboratory equipment the NS1 ELISA combined to heat dissociation could be a slightly better alternative for accurate dengue diagnosis.

\begin{abstract}
Abbreviations
Cl: Confidence interval; CNPq: Brazilian National Council of Scientific and Technological Development; DENV-1: Dengue virus serotype 1; DENV4: Dengue virus serotype 4; DNA: Deoxyribonucleic acid; ELISA: Enzymelinked immunosorbent assay; FIOCRUZ: Oswaldo Cruz Foundation; IgG: Immunoglobulin G; IOC: Instituto Oswaldo Cruz; NS1: Nonstructural protein-1; RNA: Ribonucleic acid; RT-PCR: Reverse transcriptase-polymerase chain reaction.; STARD: Standards for Reporting of Diagnostic Accuracy Study; UPA 24H: Unidade de Pronto Atendimento
\end{abstract}

\section{Acknowledgements}

We wish to acknowledge the assistance of the following: Diana Rodrigues and Fernanda Quintella, graduate students for data collection and analysis. We would also like to thank Cleber do Carmo for statistical assistance.

\section{Funding}

This study was funded by the Conselho Nacional de Desenvolvimento Científico e Tecnológico- CNPq through CNPq/PROEP 402068/2012-2 grant and CNPq/REBRATS 401366/2013 grant. SRLP is funded through CNPq 311414/2013-3 grant. The sponsors were not involved in the design, sample collection and handling, analysis, data interpretation or conclusions.

\section{Availability of data and materials}

The authors confirm that all data and materials underlying the finding are fully available without restriction with the Corresponding Author upon request.

\section{Authors' contributions}

SNB, SRLP and RPD conceived of the study, participated in its design and coordination and helped to draft the manuscript. RMRN, MRL, MHS and FBS carried out the immunoassays, rapid immunochromatographic test, viral characterization and writing the manuscript. All authors read and approved the final manuscript.

\section{Competing interests}

The authors declare that they have no competing interests.

\section{Ethics approval and consent to participate}

The Research Ethics Committee of the National Institute of Infectious Diseases Evandro Chagas - Fiocruz approved the study, CAAE 0066.0.009.000-11, on March 23, 2012. All patients signed an informed consent form.

\section{Publisher's Note}

Springer Nature remains neutral with regard to jurisdictional claims in published maps and institutional affiliations.

\section{Author details}

${ }^{1}$ National Institute of Infectious Diseases Evandro Chagas, Laboratory of Clinical Epidemiology, Oswaldo Cruz Foundation, Av. Brasil, 4036 sala 201 A Manguinhos, Rio de Janeiro CEP: 21040-361, Brazil. ${ }^{2}$ Oswaldo Cruz Institute, Instituto Oswaldo Cruz - Pavilhão Hélio e Peggy Pereira, Flavivirus Laboratory, Oswaldo Cruz Foundation, Avenida Brasil, 4365, Manguinhos, Rio de Janeiro CEP: 21040-900, Brazil. ${ }^{3}$ Germano Sinval Faria Teaching Primary Care Center, National School of Public Health, Oswaldo Cruz Foundation, Rua Leopoldo Bulhões, 1480 - Bonsucesso, Rio de Janeiro CEP: 21041-210, Brazil.

Received: 11 November 2016 Accepted: 7 March 2017

Published online: 11 March 2017

\section{References}

1. WHO. Dengue: diagnosis, treatment, prevention and control. Geneva; 2009. http://www.who.int/neglected_diseases/resources/9789241547871/en/. Accessed 15 Jan 2015

2. Simmons CP, Farrar JJ, Nguyen v V, Wills B. Dengue. N Engl J Med. 2012; 366(15):1423-32.

3. Gubler DJ. The global pandemic of dengue/dengue haemorrhagic fever: current status and prospects for the future. Ann Acad Med Singapore. 1998; 27(2):227-34.

4. Schatzmayr HG. Dengue situation in Brazil by year 2000. Mem Inst Oswaldo Cruz. 2000;95 Suppl 1:179-81.

5. Bhatt S, Gething PW, Brady OJ, Messina JP, Farlow AW, Moyes CL, et al. The global distribution and burden of denque. Nature. 2013:496(7446):504-7.

6. Messina JP, Brady OJ, Scott TW, Zou C, Pigott DM, Duda KA, et al. Global spread of dengue virus types: mapping the 70 year history. Trends Microbiol. 2014;22(3):138-46.

7. Xu H, Di B, Pan YX, Qiu LW, Wang YD, Hao W, et al. Serotype 1-specific monoclonal antibody-based antigen capture immunoassay for detection of circulating nonstructural protein NS1: Implications for early diagnosis and serotyping of dengue virus infections. J Clin Microbiol. 2006:44(8):2872-8.

8. Duong V, Ly S, Lorn Try P, Tuiskunen A, Ong S, Chroeung N, et al. Clinical and virological factors influencing the performance of a NS1 antigen-capture assay and potential use as a marker of dengue disease severity. PLoS Negl Trop Dis. 2011;5(7), e1244.

9. Lima MR, Nogueira RM, Filippis AM, Nunes PC, Sousa CS, Silva MH, et al. A simple heat dissociation method increases significantly the ELISA detection sensitivity of the nonstructural-1 glycoprotein in patients infected with DENV type-4. J Virol Methods. 2014;204:105-8.

10. Lima MR, Nogueira RM, Schatzmayr HG, dos Santos FB. Comparison of three commercially available dengue NS1 antigen capture assays for acute diagnosis of dengue in Brazil. PLoS Negl Trop Dis. 2010;4(7), e738.

11. Lima MR, Nogueira RM, de Filippis AM B, dos Santos FB. Comparison of two generations of the Panbio dengue NS1 capture enzyme-linked immunosorbent assay. Clin Vaccine Immunol. 2011;18(6):1031-3.

12. da Costa VG, Marques-Silva AC, Moreli ML. A meta-analysis of the diagnostic accuracy of two commercial NS1 antigen ELISA tests for early dengue virus detection. PLoS One. 2014;9(4), e94655.

13. Pal S, Dauner AL, Mitra I, Forshey BM, Garcia P, Morrison AC, et al. Evaluation of dengue NS1 antigen rapid tests and ELISA kits using clinical samples. PLoS One. 2014;9(11), e113411.

14. Sea VR, Cruz AC, Gurgel RQ, Nunes BT, Silva EV, Dolabella SS, et al. Underreporting of Dengue-4 in Brazil due to low sensitivity of the NS1 Ag test in routine control programs. PLoS One. 2013;8(5), e64056.

15. Koraka P, Burghoorn-Maas CP, Falconar A, Setiati TE, Djamiatun K, Groen J et al. Detection of immune-complex-dissociated nonstructural-1 antigen in patients with acute dengue virus infections. J Clin Microbiol. 2003;41(9):4154-9. 
16. Schüpbach J, Böni J. Quantitative and sensitive detection of immune-complexed and free HIV antigen after boiling of serum. J Virol Methods. 1993:43(2):247-56.

17. Bossuyt PM, Reitsma JB, Bruns DE, Gatsonis CA, Glasziou PP, Irwig LM, et al. Toward complete and accurate reporting of studies of diagnostic accuracy. The STARD initiative. Am J Clin Pathol. 2003;119(1):18-22.

18. Brasil $P$, Calvet GA, Siqueira AM, Wakimoto M, de Sequeira PC, Nobre A, et al. Zika Virus Outbreak in Rio de Janeiro, Brazil: Clinical Characterization, Epidemiological and Virological Aspects. PLoS Negl Trop Dis. 2016;10(4), e0004636.

19. Lima MRQ, Nogueira RM, Santos FB. Dengue diagnosis: commercially available kits and laboratory support. In: Clinical insights: dengue: transmission, diagnosis \& surveillance. 1st ed. London: Future Medicine Ltd; 2014. p. 27-47.

20. Lanciotti RS, Calisher CH, Gubler DJ, Chang GJ, Vorndam AV. Rapid detection and typing of dengue viruses from clinical samples by using reverse transcriptase-polymerase chain reaction. J Clin Microbiol. 1992; 30(3):545-51.

21. Buonora SN, Passos SR, do Carmo CN, Quintela FM, de Oliveira DN, dos Santos FB, et al. Accuracy of clinical criteria and an immunochromatographic strip test for dengue diagnosis in a DENV-4 epidemic. BMC Infect Dis. 2016;16(1):37.

22. Falconar AK, Young PR. Immunoaffinity purification of native dimer forms of the flavivirus non-structural glycoprotein, NS1. J Virol Methods. 1990;30(3):323-32.

23. Lapphra K, Sangcharaswichai A, Chokephaibulkit K, Tiengrim S, Piriyakarnsakul W, Chakorn T, et al. Evaluation of an NS1 antigen detection for diagnosis of acute dengue infection in patients with acute febrile illness. Diagn Microbiol Infect Dis. 2008;60(4):387-91.

\section{Submit your next manuscript to BioMed Central and we will help you at every step:}

- We accept pre-submission inquiries

- Our selector tool helps you to find the most relevant journal

- We provide round the clock customer support

- Convenient online submission

- Thorough peer review

- Inclusion in PubMed and all major indexing services

- Maximum visibility for your research

Submit your manuscript at www.biomedcentral.com/submit
Biomed Central 